\title{
THE IT STRATEGY AND PERCEPTION OF BARRIERS FACED BY POLISH MANUFACTURING SMES IN THE IMPLEMENTATION OF CLOUD COMPUTING
}

\author{
Anna PAMUŁA \\ Faculty of Management, University of Lodz; anna.pamula@uni.lodz.pl, ORCID: 0000-0001-6597-8622
}

\begin{abstract}
Purpose: The aim of the paper was to analyse barriers to adopting Cloud Computing solutions by small and medium-sized manufacturing enterprises in Poland.

Design/methodology/approach: The paper is based on the review of literature and studies on the application of Cloud Computing solutions in small and medium-sized enterprises as well as the results of own research among this group of enterprises. Quantitative research was carried out using a survey questionnaire in December 2017 - February 2018, with the use of the CATI technique, among manufacturing enterprises in Poland.

Findings: Investigated SMEs see fewer and fewer barriers in the implementation of new CC models. In the surveyed group most barriers are perceived by less than $30 \%$ of respondents. Research limitations/implications: A certain limitation of the study is that no separate Digital Business Strategy or Agile Strategy were considered, assuming that they were included in the adopted survey options. This result could have been influenced by the period in which the research was carried out, which is less than half a year before the entry into force of the General Data Protection Regulation - GDPR.

Originality/value: The perception of barriers is discussed taking into account the application of an IT Strategy and the party responsible for the implementation.
\end{abstract}

Keywords: Cloud Computing, IT Strategy, manufacturing, IT.

Category of the paper: Research paper.

\section{Introduction}

Innovations in the manufacturing industry are necessary and must gain momentum so that organisations can meet the challenges of improving product quality and fulfilling new customer expectations. The wave of the new industrial revolution means that manufacturing is strongly supported by new technologies such as Cloud Computing (CC) and Big Data Analytics (BD) integrated with material resources and means of production of the organisation. The role that $\mathrm{CC}$ can fulfil goes beyond the mere impact of technology and has a strong influence on the 
improvement of business processes, cooperation with other supply chain entities as well as the entire business and social environment. The integration of CC solutions implementation with production processes and systems, along with a shift of the communication system to the real mode, facilitates global enterprise management. The implementation of CC solutions requires the organisation to define a strategy of conduct and to build a road map leading to the achievement of the set goals determining, among others, the choice of the cloud services model and the desired scope of competences, or even the entire strategic model of Cloud Computing and Cloud Manufacturing implementation (Alkhlil, Sahandi and John, 2013; Yuqiuge, 2016).

The key factor to a company's success in a dynamic environment is an effective and efficient information technology supporting business strategies and processes. Organisations that successfully adapt their Business Strategy and IT Strategy achieve better results in the implementation of IT technologies (Silvus, 2007). Changes related to ICT implementation concern all enterprises. Most SMEs, however, do not implement new ICT technologies as fast as large corporations, encountering many barriers related to their adoption (Arendt, 2007).

Scientific research on barriers that SMEs perceive in the adoption of ICT solutions is not a new subject and many of its issues have been developed both as part of national and global studies. This paper focuses in its empirical part on the impact that adopting an IT Strategy and the application of a specific model for the implementation of Cloud Computing solutions in the organisation have on the perception of barriers.

\section{Cloud Computing and Cloud Manufacturing}

The implementation of the $\mathrm{CC}$ model means a paradigm shift both within business infrastructure and IT infrastructure. The basis of Cloud Computing is the evolution of several business trends, especially the emergence and strong expansion of the "pay-as-you-go/use" business model, and technological trends, for example, virtualisation, distributed computing, mass storage, scalability or content outsourcing.

In manufacturing enterprises, the trend of servitisation associated with the transition from offering products to offering services has been observed for years and is characterised not only by satisfying the growing needs of customers but most of all by creating value (HAO Baines et al., 2009). As early as in the 1970s, Bell (1973) argued that knowledge-based services would raise production to a new level as a growth engine for the production economy.

Currently, $\mathrm{CC}$ is gradually becoming one of the main factors enabling the manufacturing industry to achieve business goals in the field of high-level cooperation with partners. Manufacturing enterprises can act rationally and accept the concept of Cloud Computing to create a production version of $\mathrm{CC}$ referred to as Cloud Manufacturing (Sierska and Jaada, 2018). Cloud Computing is starting to refer not only to technology but to a more broadly 
understood synergy effect resulting from the combination of state-of-the-art technologies, ensuring a secure and reliable service platform at relatively low prices and supporting the entire production cycle (Xu, 2012).

The concept of Manufacturing Cloud means on-line cooperation and communication of all partners in all aspects of ecosystem production operations where users make use of services and virtual resources available in the cloud in order to perform assigned on-demand production tasks (Sierska and Jaada, 2018).

In order to meet these challenges and create a dedicated production environment in the cloud, it is important to create an appropriate strategy taking into account the measurement of the quality of services provided by monitoring performance and improving SLAs (Service Level Agreement) while ensuring that business services supported by IT services provided in the $\mathrm{CC}$ model correspond to the level expected by clients (Xu, 2013).

\section{Business and IT Alignment in SMEs}

In the traditional Enterprise Architecture (EA), the creation of a strategic IT plan usually complements the Business Strategy adopted in the organisation and allows it to achieve a better alignment in terms of business goals and IT goals as well as to reduce the risk associated with the implementation of IT solutions. The organisation's IT Strategy usually defines IT technologies, applications and services, as well as competences and processes necessary to achieve its business objectives. Creating the IT Strategy allows for the analysis of the weaknesses of currently owned IT solutions in order to propose new ones, and it may become the basis for the construction of a roadmap to improve the organisation's functioning in the area of exploiting business opportunities.

The decision to create and implement an IT Strategy may be caused by many factors, such as: recommendations from the audit performed, changes in the management system, the need to meet market challenges and customer expectations, observations of actions taken by competitors, or changes in the organisation's environment.

The adoption of IT Strategies also involves identifying issues related to IT supervision, and thus the challenges that need to be addressed to ensure that the provision of IT services complies with generally accepted principles of good practice, such as ITIL (IT Infrastructure Library) or CMMI (Capability Maturity Model ${ }^{\circledR}$ Integration).

The need to match IT to business needs is documented by many studies considering many perspectives and aspects. The first models appeared along with the increase in the number of IT systems and the development of their functionality, which resulted in the need to adapt them to business processes and organisational strategies. Methodologies for planning IT systems and system development created during that period were mainly based on the analysis of business 
processes and data flow. The methods that support the creation of large tailored MRP-type information systems can be considered as the early emergence of Business IT Alignment (BIA). Those methods did not take into account a wider perspective related to the effectiveness of implemented IT solutions (Silvus, 2009). Another approach, Strategic Information Systems, combined the methods, processes and implementation, offering a complete way of planning IT systems and treating them as investments, stressing the importance of strategic fit of IT and Business as well as the achieved business results (Doherty, et al., 1999).

Strategic BIA refers to the alignment of the Business Strategy, plans and priorities with the IT Strategy, plans and priorities (Weiss and Thorogood, 2011). Organisations that adapt their Business Strategy well to their IT Strategy achieve better results and therefore the relationship between the Business Strategy and the IT Strategy is an important area of research (Smits et al., 2009).

In manufacturing enterprises, BIA relies on promoting coherence between business and production processes in order to gain a competitive advantage (Silvus et al., 2009), which in the Industry 4.0 era means meeting the challenges in the construction of ecosystems and Cloud Manufacturing. In order to implement a system supporting all activities related to manufacturing in the cloud, we need a synchronised system that is strictly related to organisational strategic management, including production, responsible for providing $\mathrm{CC}$ technology support for individual resources, products and operations in processes.

EA indicates a subordinate dependence of the IT Strategy to the Business Strategy. Silvus (2007) has shown that every Business Strategy can be supported by all IT Strategies, though some combinations provide a better Business-IT fit than others. His research indicates that some organisations perceive IT only as a factor supporting business processes, while others as the driving force of business innovations allowing for the creation of a competitive advantage in the market. In the latter case, a higher level of Business IT alignment is obtained, which results in the conclusion that a more progressive IT Strategy is associated with a better fit of Business and IT (Silvus, 2007). BIA-related problems often stem from the fact that IT managers are not always aware of the corporate strategy and organisational leaders do not always have knowledge about IT (Seman and Salim, 2013).

The Industry 4.0 era resulted in the emergence of the concept of the Digital Strategy, in which there is no subordination of the IT Strategy to the Business Strategy, as they are equivalent (Bharadwaj et al., 2013). Currently EA is facing new challenges, as more and more often organisations use Agile Business Development, and ecosystems as well as smart products are becoming part of architecture, which requires holistic planning for digital production transformations of SMEs (Goerzig and Bauernhansl, 2018).

Business and IT planning enables business and IT management to collaborate in managing challenges and opportunities related to technology. The IT Strategy cannot be adapted to the Business Strategy if organisations do not have formal planning processes, and Business Strategies are not clear, which makes the achievement of BIA difficult (Seman and Salim, 
2013). In the research of small and medium enterprises, only a few have achieved B-IT alignment, which may be due to the fact that the structure of small and medium-sized companies is based more on the functional approach to task completion, while management is centralised (Seman and Salim, 2013). SMEs usually focus on the practical achievement of tangible or intangible goals through simple tasks, while large enterprises are more open to innovative new adaptations (Barann et al., 2019).

In practice, organisations, including SMEs, often have problems developing strategies that allow them to use the effects of implementing new ICT technologies. This is confirmed by many reports and studies, among others, the EU document "Fostering SMEs growth through digital transformation" placed at EU Smart Specialisation Platform, stating that SMEs are struggling with much greater difficulties than large companies while undertaking activities related to the pursuit of digital transformation. Research conducted by Computer Weekly in Great Britain has indicated that only $49 \%$ of respondents (SMEs managers) admitted that their company had the IT Strategy, and in $58 \%$ the strategy was formulated by the IT manager (Computer Weekly, 2003). Although the research is not the latest, this trend has not changed significantly, but the role of CIO is becoming more important (PWC, 2017). Nevertheless, the degree of the use of IT technologies, including the Internet and applications related to business process support, is increasing (Ardent, 2007). The maturity level of SMEs' Digital Transformation is also diversified across EU countries. Studies carried out in Singapore show that SMEs are slowly starting to implement IT strategies related to the CC implementation (Gupta et al., 2013), and the perception of barriers and benefits depends on the geographical location. Companies in Europe, Asia or North America perceive and implement solutions differently. Companies from Latin America, Asia and the Pacific are the most aggressive users of Cloud Computing (Gupta et.al., 2013).

\section{Barriers to ICT and CC adoption in SMEs}

The subject of barriers encountered by SMEs has been widely studied and developed, resulting in a series of classifications and approaches (Arendt, 2007). One of the classifications divides the barriers into two major categories: the macro-economic category (related to a lack of appropriate market effect for the leaders implementing innovations, low elasticity of the production environment or a lack of new-generation infrastructure) and the micro-economic category (a lack of knowledge and skills, low levels of awareness about potential benefits, a lack of adaptation of the education system to the rapid changes in technology, a lack of appropriate solutions for the digital economy) (Arendt, 2007). Another classification, associated mainly with the implementation of e-business solutions, highlights barriers related 
to: a lack of suitability for the organisation, a lack of infrastructure and personnel resources, the cost of implementation, as well as security and protection (Ardent, 2007).

When examining CC development prospects in Poland, Dziembek (2018) distinguishes barriers related to security, legal barriers, technical, psychological and market barriers. Research related to CC adoption in Poland carried out by (Słaby and Dwojak, 2017) encompassed five groups of barriers: behavioural barriers (related to the experiences, attitudes and opinions of project stakeholders), organisational barriers (related to the determinants of the implementation entity, including sponsor support or compliance with the strategy), securityrelated barriers (resulting from legal regulations and confidentiality of company and client data), financial barriers (costs, financing methods, expected benefits), and technical barriers (infrastructure-related). The study has shown that the first of these groups had the greatest importance followed by a group associated with organisational barriers. Among Polish companies, there are also mentality barriers related to concerns about various risks associated with Cloud Computing, such as attachment to already existing traditional IT solutions or limited trust in new offers (Parys, 2015, Krok, 2017). On the other hand, research carried out in Romania on barriers related to the implementation of Industry 4.0 technology has shown that not only barriers related to a lack of competences or standards are an obstacle to implementation, but above all, a lack of knowledge and understanding of Industry 4.0 (Türkes et al., 2019), while and still for some developing countries the main obstacles are security issues and insufficient financial support (Al Mabhouh and Alzaza, 2015).

Most earlier studies confirm that the basic barrier to the implementation of ICT technology in SMEs is the cost. This barrier in the case of CC, by providing scalable solutions, is reduced. The indisputable advantages of $\mathrm{CC}$ are the avoidance of high initial costs, flexibility and scalability (Parys, 2015).

At the time when cloud solutions were just emerging as services, the reason why companies reluctantly adopted the cloud was connected with the uncertainty concerning security. Today, many of these fears have disappeared, as the experience of companies shows that the main providers of cloud services have resources and experience that enable them in most cases to provide a higher level of security than in the case of on-premise traditional solutions. Currently, in terms of data, the psychological element is coming to the fore, as well as the practical element related to the fear of losing control over the data (Palos-Sanchez, 2017).

In the literature, one can also find studies that have shown the impact of other organisations on SMEs' propensity for implementing new IT solutions, which may especially apply to companies connected in an integrated supply chain or suppliers of large retail chains. The proposed new models of industrial value chains for the Industry 4.0 (new industrial value chains) (Oleśków Szłapka et al., 2017) can therefore support SMEs in making decisions about innovations and contribute to eliminating barriers.

It should be noted that both requirements related to implementation and tools supporting business operations of SMEs in Poland are simpler compared to large companies. 
In the case of implementing comprehensive solutions, large enterprises usually use services of external consultants or consulting companies to ensure the right quality of the solution. SMEs, especially micro and small enterprises, can rarely afford this type of assistance (the 3rdParty support), but they can also use another source, namely co-financing of innovative activities from public funds (Barann et al., 2019).

\section{Research Methodology}

As part of the presented study, manufacturing enterprises from the sector of small and medium-sized enterprises were analysed in the context of perceiving barriers related to the adoption of CC solutions.

This research problem, although it has been intensely explored as shown in the previous part of the paper, remains a current one, since Cloud Computing and Cloud Manufacturing are still solutions in the initial phase of evolution which are being gradually developed. The new model of industrialisation - Industry 4.0 - to which Poland, Europe and the world aspire, makes it very important to constantly conduct research in this field. Polish SMEs are struggling with a number of barriers during the implementation of new ICT technologies, and the degree of maturity of CC solutions is not high. Taking into consideration the role of IT strategy in BIA and the responsibility of the party implementing the solution, the following three research questions were posed:

RQ1: How do Polish manufacturing SMEs perceive barriers to the adoption of Cloud Computing?

RQ2: Does the IT Strategy influence this perception?

RQ3: Does the responsibility for the implementation process influence this perception?

The survey method was used to answer these questions and an appropriate questionnaire was prepared for this purpose. The research carried out was aimed at the identification of the $\mathrm{CC}$ adoption status in Polish manufacturing enterprises. This analysis focuses only on barriers perceived by SMEs. The selection of the sample for the study was conducted on the basis of random selection, the study was performed by a specialised research agency. Respondents were middle-level managers or owners in the case of micro-enterprises. The survey screening question concerned the number of services implemented in the $\mathrm{CC}$ model - the main questions of the survey were addressed to companies that implemented business process support services other than e-mail. A pilot study was conducted using the CATI method at the beginning of December 2017, the main study was carried out in December 2017 and January 2018. 277 completed responses were obtained. Seven of them contained incorrect data and were rejected from the study. 
The group surveyed was dominated by medium-sized enterprises (over 50\%), in terms of capital structure, enterprises with Polish capital dominated, constituting over $85 \%$ of companies (Figure 1), as well as enterprises conducting international market activities $-58.90 \%$ (Figure 2).

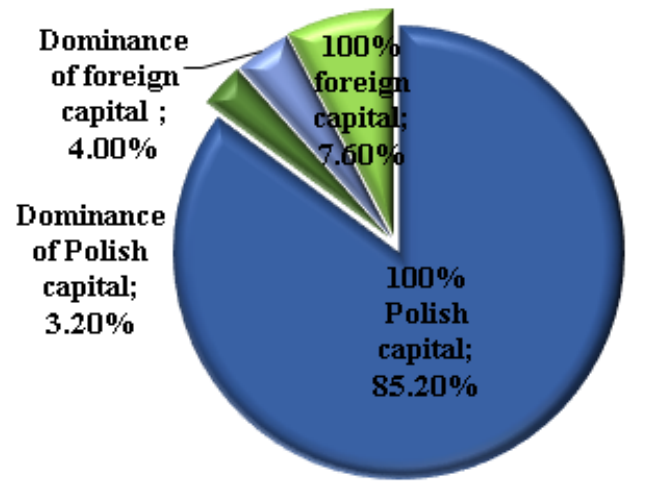

Figure 1. Capital structure of the surveyed enterprises. Source: Own compilation.

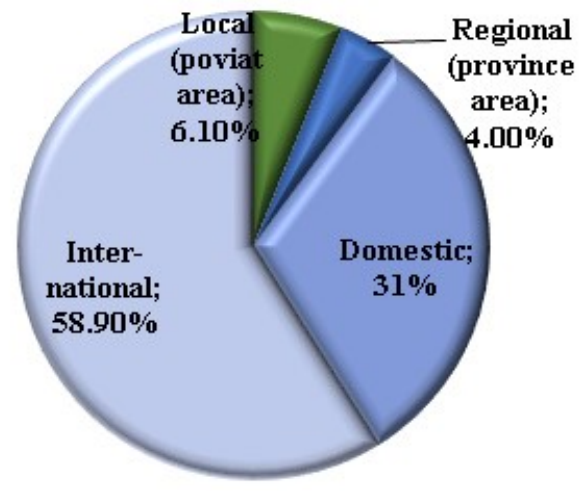

Figure 2. Spatial range of market activity of the surveyed enterprises. Source: Own compilation.

Based on the literature review, the following barriers were selected for the study:

- Personal data protection issues (in the tables and figures referred to as B1: Data privacy),

- Legal aspects (in the tables and figures referred to as B2: Legal issues),

- A low degree of trust in new technologies (B3: Limited trust in new technologies),

- Uncertainty concerning the security of data and services (B4: Concerns about the security of data and services),

- Concerns about the conduct of cloud service providers (in the tables and figures referred to as B5: CC provider bad practices),

- Implementation costs (in the tables and figures referred to as B6: Costs),

- Difficulties with the integration of solutions (in the tables and figures referred to as $B 7$ : Integration problems),

- Concerns about the quality of services provided by cloud providers (in the tables and figures referred to as B8: Quality of CC providers services),

- Difficulty with Internet access due to a poor Internet connection (in the tables and figures referred to as B8: Poor Internet connection),

- An insufficient level of knowledge and competences (in the tables and figures referred to as B10: Lack of knowledge and competences),

- Unknown influence on company management (in the tables and figures referred to as B11: Unknown impact on business),

- Complexity of Service Level Agreements (SLAs) (in the tables and figures referred to as $B 12: S L A)$.

This set of barriers was analysed for each of the three research questions. 
Considering the topic of the second research question regarding the impact of the IT Strategy on the perception of barriers, the following options were examined with the respondent choosing only one:

- The organisation has the IT Strategy aligned with its Business Strategy (in the tables and figures referred to as IT Strategy aligned with BS),

- The organisation has the IT Strategy independent from its Business Strategy (in the tables and figures referred to as Own IT Strategy),

- The organisation has the IT Strategy but the respondent cannot determine its correlation with its Business Strategy (the option added after the pilot study) (in the tables and figures referred to as Applied IT Strategy),

- The organisation has no IT Strategy (in the tables and figures referred to as No IT Strategy).

For the third research question, concerning the responsibility for conducting the implementation process, three options to choose from were adopted without limiting the number of responses:

- Cloud Computing services supplier (in the tables and figures referred to as CC Supplier),

- own IT department (in the tables and figures referred to as IT dept.),

- the third party company (in the tables and figures referred to as the 3rd Party).

\section{Results and discussion}

Analysing the results related to RQ1: How do Polish manufacturing SMEs perceive barriers to the adoption of Cloud Computing?, it was examined how micro, small and medium-sized enterprises perceive those barriers. Analyses of descriptive statistics were conducted. In most cases there is no statistically significant dependence between the perception of barriers and the size of the enterprise, only in the case of B3: Limited trust in new technologies and B5: $C C$ provider bad practices, this dependence is statistically significant. The analysis of the perception of barriers by micro, small and medium enterprises is presented in Table 1. Analysing the distribution of responses for individual company sizes, it should be noted that respondents from medium-sized enterprises more often point to barriers related to suppliers' practices and legal issues than respondents from micro and small enterprises (Figure 3). Respondents were not asked in detail about experiences of their companies, but this may be due to those experiences, as the study examined companies that had implemented CC. It should be noted that compared to previous studies, costs have ceased to be seen as a very important barrier. Only $23 \%$ of respondents from medium-sized companies, $18 \%$ from small and $12 \%$ from micro ones perceive costs as a barrier, which may also be caused by the experience of using services in the $\mathrm{CC}$ model. Concerns about access to services due to a poor Internet connection are still a rather significant barrier (36\% of small and $34 \%$ of medium-sized companies). These responses may indicate a generally low level of ICT SMEs maturity in 
Poland. It should be added that three respondents did not specify any of the barriers examined as significant.

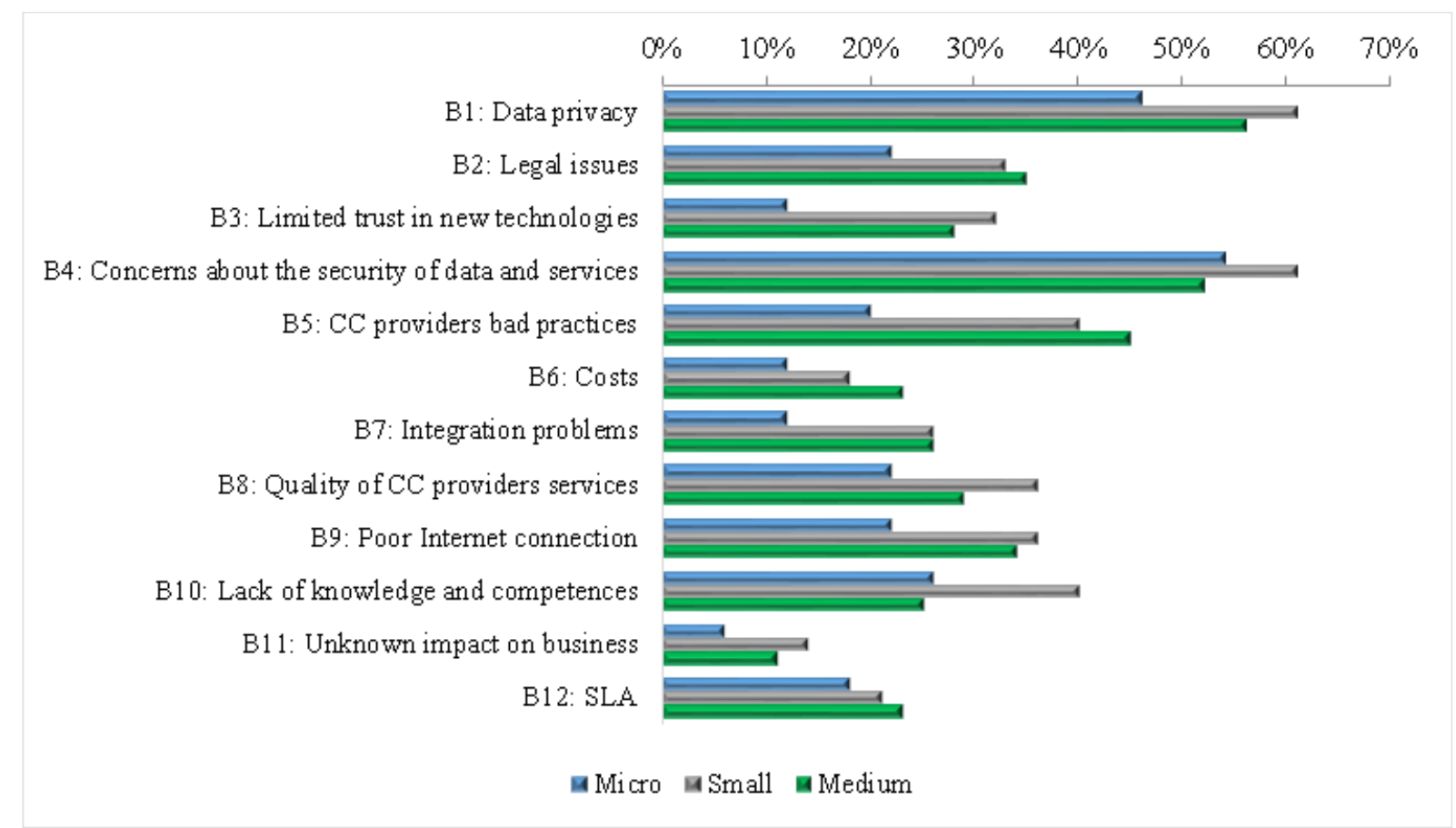

Figure 3. Perception of barriers by micro, small and medium-sized enterprises. Source: Own compilation.

Table1.

Percentage of respondents perceiving the barrier as significant

\begin{tabular}{|l|c|c|c|}
\hline \multicolumn{1}{|c|}{ Barrier } & Micro & Small & Medium \\
\hline B1: Data privacy & $46 \%$ & $61 \%$ & $56 \%$ \\
\hline B2: Legal issues & $22 \%$ & $33 \%$ & $35 \%$ \\
\hline B3: Limited trust in new technologies & $12 \%$ & $32 \%$ & $28 \%$ \\
\hline B4: Concerns about the security of data and services & $54 \%$ & $61 \%$ & $52 \%$ \\
\hline B5: CC providers bad practices & $20 \%$ & $40 \%$ & $45 \%$ \\
\hline B6: Costs & $12 \%$ & $18 \%$ & $23 \%$ \\
\hline B7: Integration problems & $12 \%$ & $26 \%$ & $26 \%$ \\
\hline B8: Quality of CC providers services & $22 \%$ & $36 \%$ & $29 \%$ \\
\hline B9: Poor Internet connection & $22 \%$ & $36 \%$ & $34 \%$ \\
\hline B10: Lack of knowledge and competences & $26 \%$ & $40 \%$ & $25 \%$ \\
\hline B11: Unknown impact on business & $6 \%$ & $14 \%$ & $11 \%$ \\
\hline B12: SLA & $18 \%$ & $21 \%$ & $23 \%$ \\
\hline S6inc: Own compiling
\end{tabular}

Source: Own compilation.

Analysing the results related to RQ1: Does the IT Strategy influence this perception?, the impact of individual IT Strategy options on the perception of barriers was examined. Analyses of descriptive statistics were conducted. In most cases, there is a lack of statistically significant dependence between the barrier perception and the type of implemented IT Strategy. Only in the case of barrier B10, related to the lack of knowledge and competences, this relationship is strong, and for two barriers: B4 (Concerns about the security of data and 
services) and B9 (Difficulty with Internet access due to a poor Internet connection), there is a weak dependence. Perception results are presented in the chart in Figure 4.

In the case when the company has no IT Strategy the barrier B4 related to data and services security was often indicated.

In the case when the company has the IT Strategy independent from its Business Strategy (Own IT Strategy), the barrier that is clearly more often perceived is B9 Difficulty with Internet access due to a poor Internet connection (Figure 5). In case of the barrier B10 the perception is almost the same for companies with Own IT Strategy and with No strategy, while it is the smallest for companies with IT strategy aligned with the business strategy.

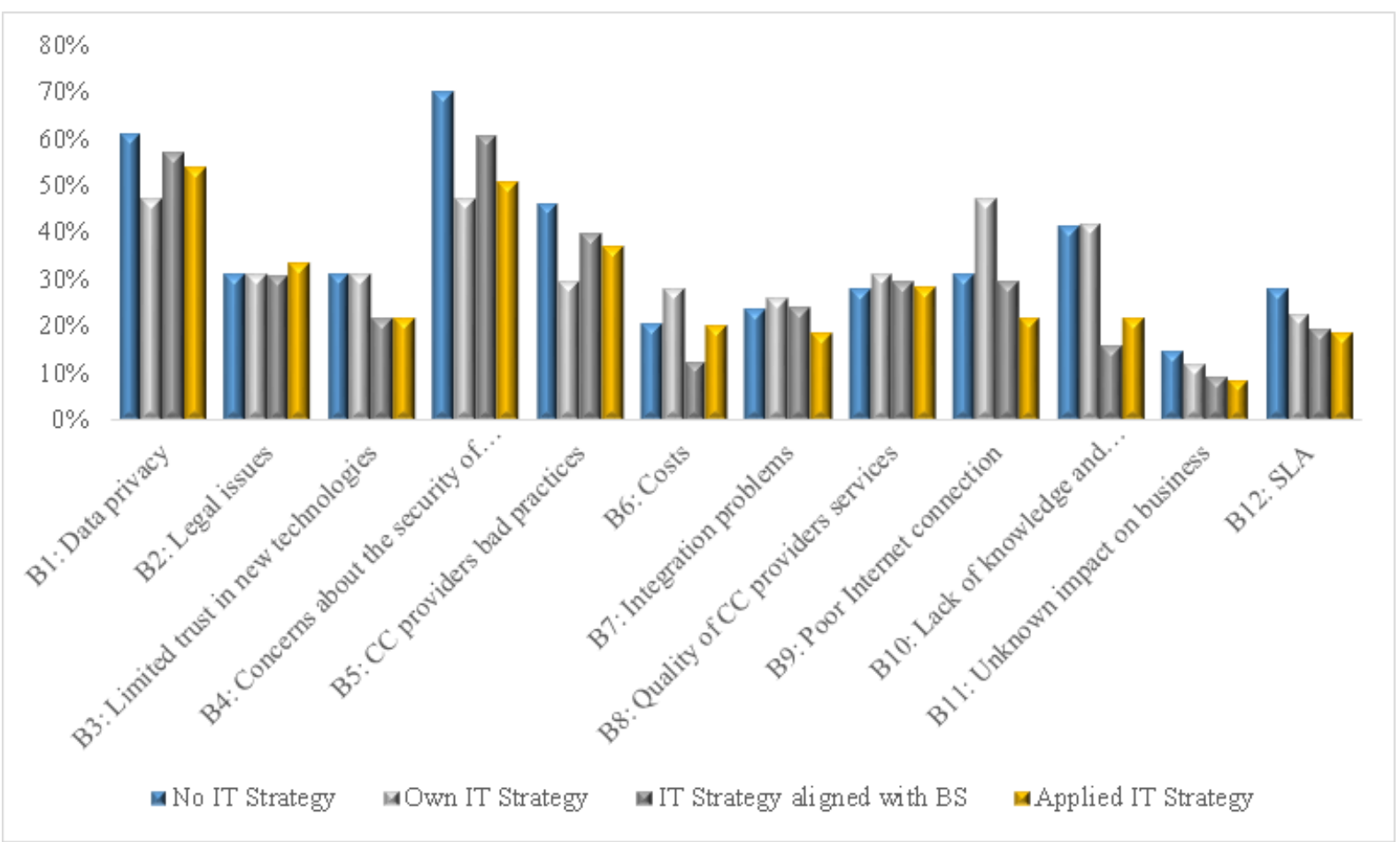

Figure 4. Perception of barriers depending on the adopted IT strategy. Source: Own compilation.

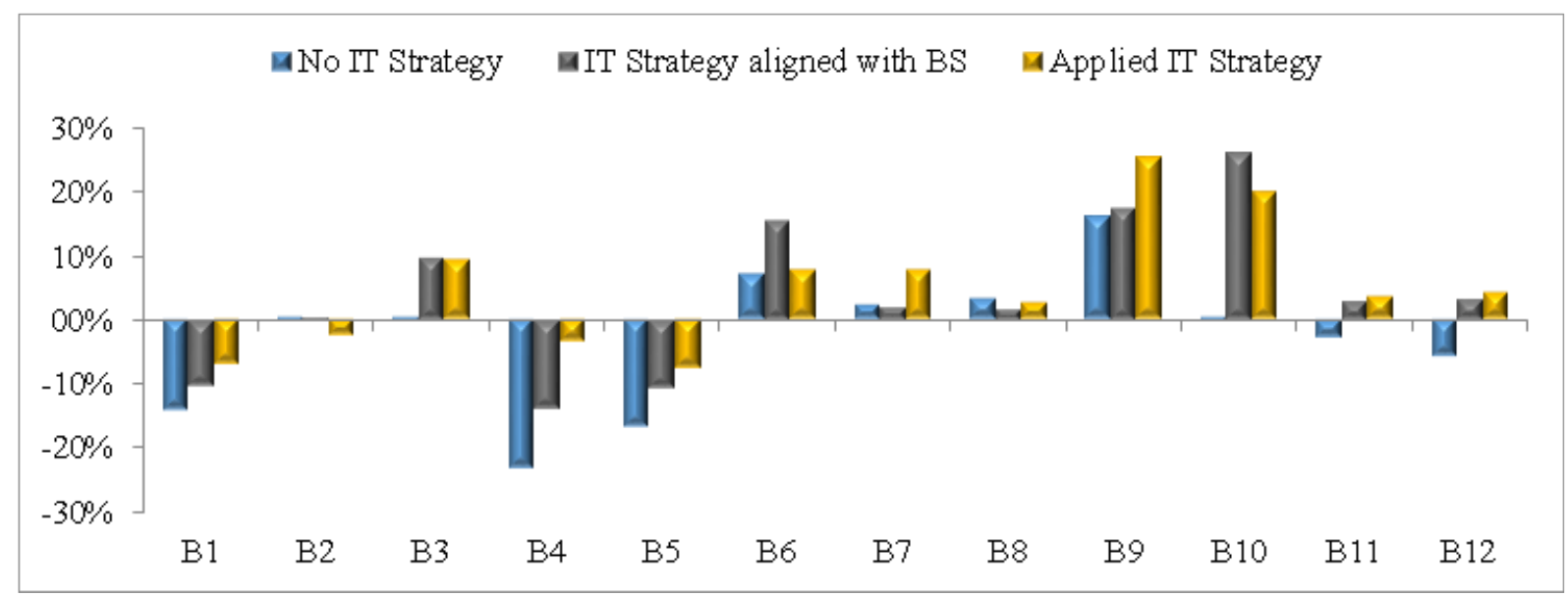

Figure 5. IT Perception of barriers in the case of own IT Strategy in relation to other IT Strategy options. Source: Own compilation. 
If the IT Strategy implemented by the organisation is aligned with its Business Strategy, respondents more often perceive barrier B4, while barrier B10 associated with a lack of knowledge and competences is much less important (compared to the Own IT Strategy situation by $26 \%$ ) (Figure 6 ).

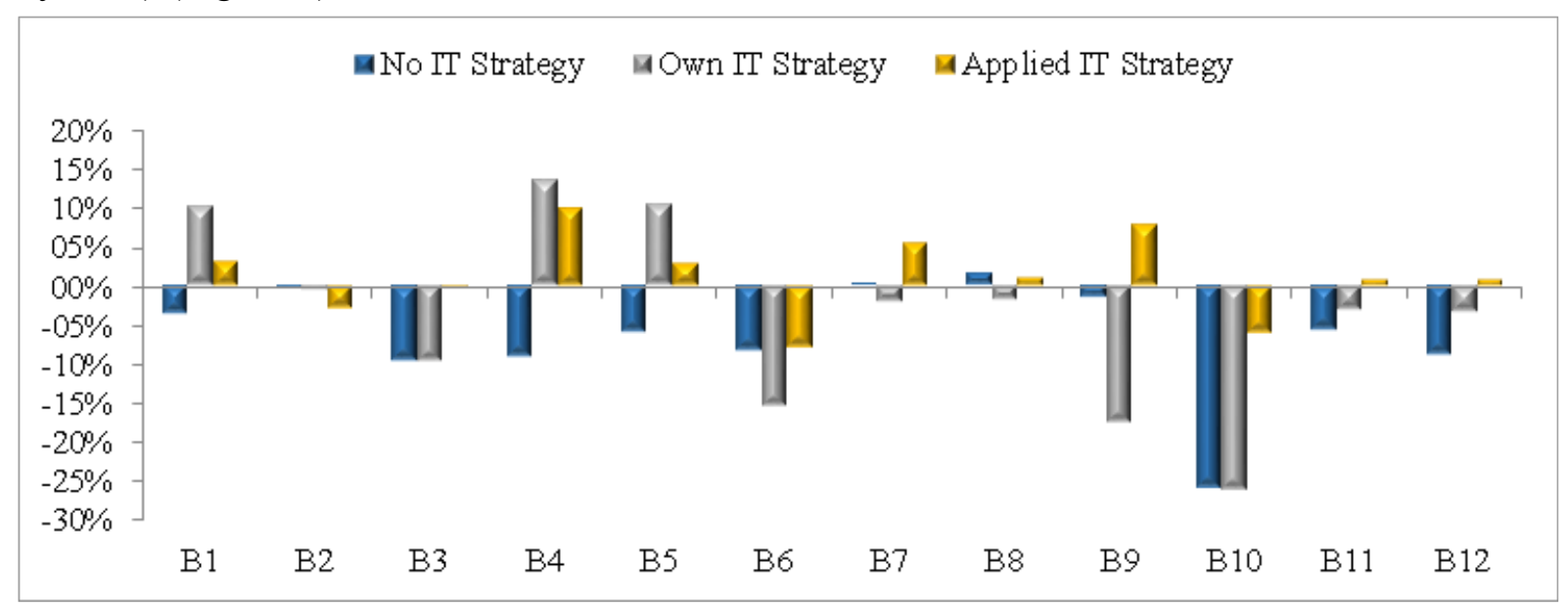

Figure 6. Perception of barriers in the case of the IT Strategy aligned with the Business Strategy in relation to other IT Strategy options. Source: Own compilation.

For the analysis of the case when The organisation has no IT strategy, a comparison was made by cumulating the options of owning a strategy (IT Strategy aligned with the Business Strategy, Applied IT Strategy). Analyses of descriptive statistics were conducted. In most cases, there is a lack of statistically significant dependence between the perception of barriers and the type of implemented IT Strategy, though there is a statistically significant dependence between the IT Strategy and the barriers related to B4: Concerns about the security of data and services as well as B10: Lack of knowledge and competences. As a result of this analysis, it can be stated that these two barriers are perceived more often when there is no adopted IT Strategy in the organisation. Additionally, analysing the remaining responses, it can be seen that barrier B4 (Concerns about the security of data and services) and barrier B10 (Lack of knowledge and competences) were perceived more often in the analysed group. The differences in barriers perception are presented in table 7. Because only two out of 12 barriers have such a conclusion it cannot be said that having the IT Strategy in place has a positive impact on the implementation of CC solutions, thus reducing the perception of barriers. It can be the result of the number of organizations surveyed and still remains an open question to investigate. 


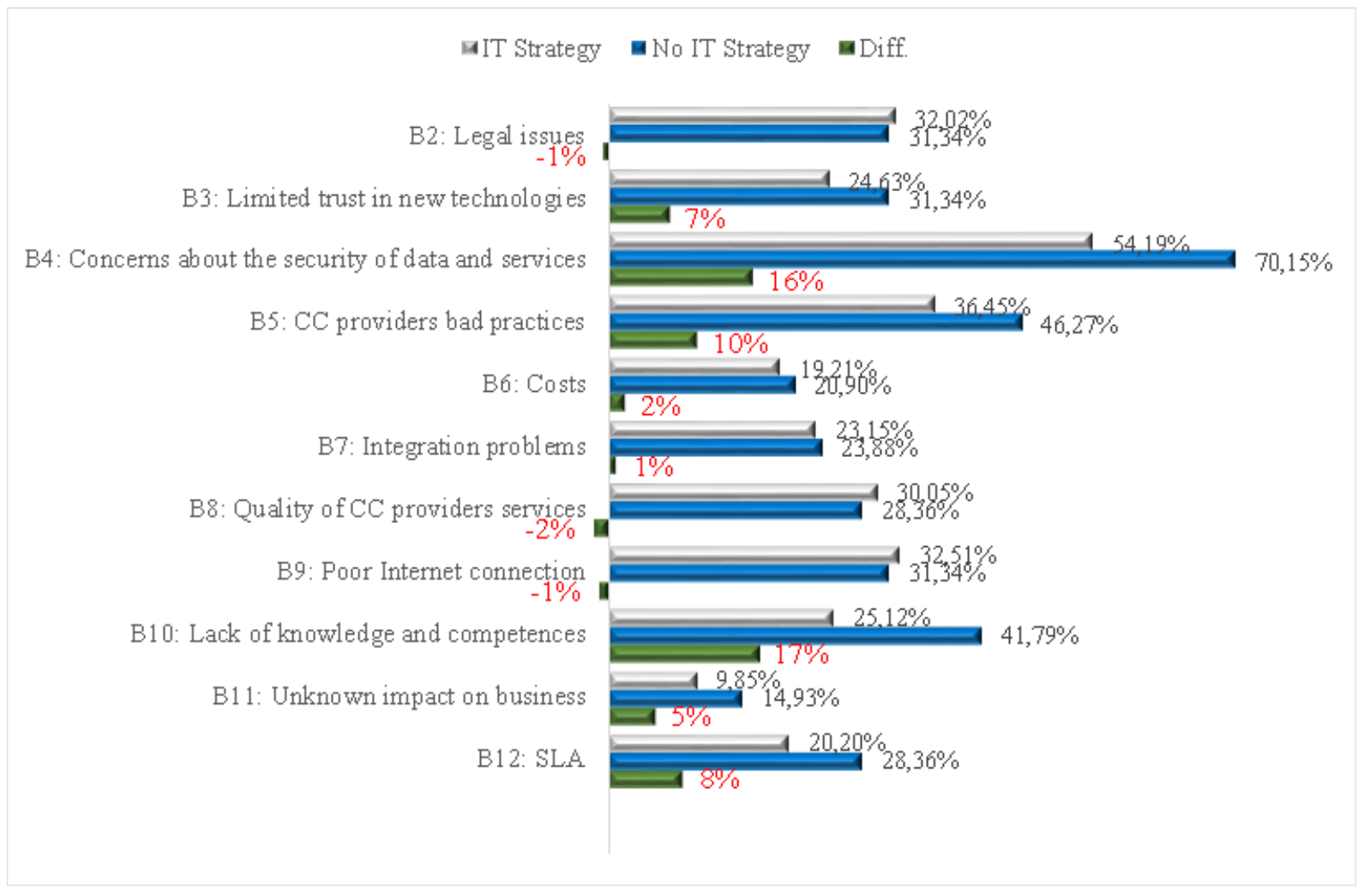

Figure 7. Perception of barriers in the case of No IT Strategy in relation to having the IT Strategy in place. Source: Own compilation.

Analysing the results related to RQ3: Does the responsibility for the implementation process influence this perception?, the influence of individual implementation options on the perception of barriers was examined. In this question, respondents had multiple answer options to choose from. The analysis was conducted for the following system: only CC supplier, only IT Dept., only 3rd Party, each multiple selection was assigned to the Shared option (each indicated combination of the three mentioned options). Detailed results of the analyses are presented in Figure 8. Most of the barriers are indicated more often if the IT Department is responsible for the implementation, with the exception of the barrier related to implementation costs, which may result from the fact that some of the tasks in this case are performed as part of the team's previous responsibilities. In turn, if the implementation is carried out by the $\mathrm{CC}$ services supplier, the perception of barriers is less frequent, especially in the case of barriers related to Integration problems. The implementation carried out by the 3rd Party means that in most cases SMEs perceive barriers less frequently (for 7 barriers) than when their own IT Department is responsible for the implementation, but more often in a situation when the CC services supplier is responsible for the implementation (for 9 barriers). In this case, it was also observed that the barrier of Limited trust in new technology was much more often perceived. A joint responsibility means in practice certain responsibilities of each party. This model shows a reduction in the perception of barriers in relation to the model with the implementation carried out by the organisation's own IT Department (for 8 barriers), but an increase in relation to the model in which the $\mathrm{CC}$ services supplier is responsible for the implementation (for 9 barriers). Thus, the entity implementing the CC solution has an impact on the perception of barriers. 


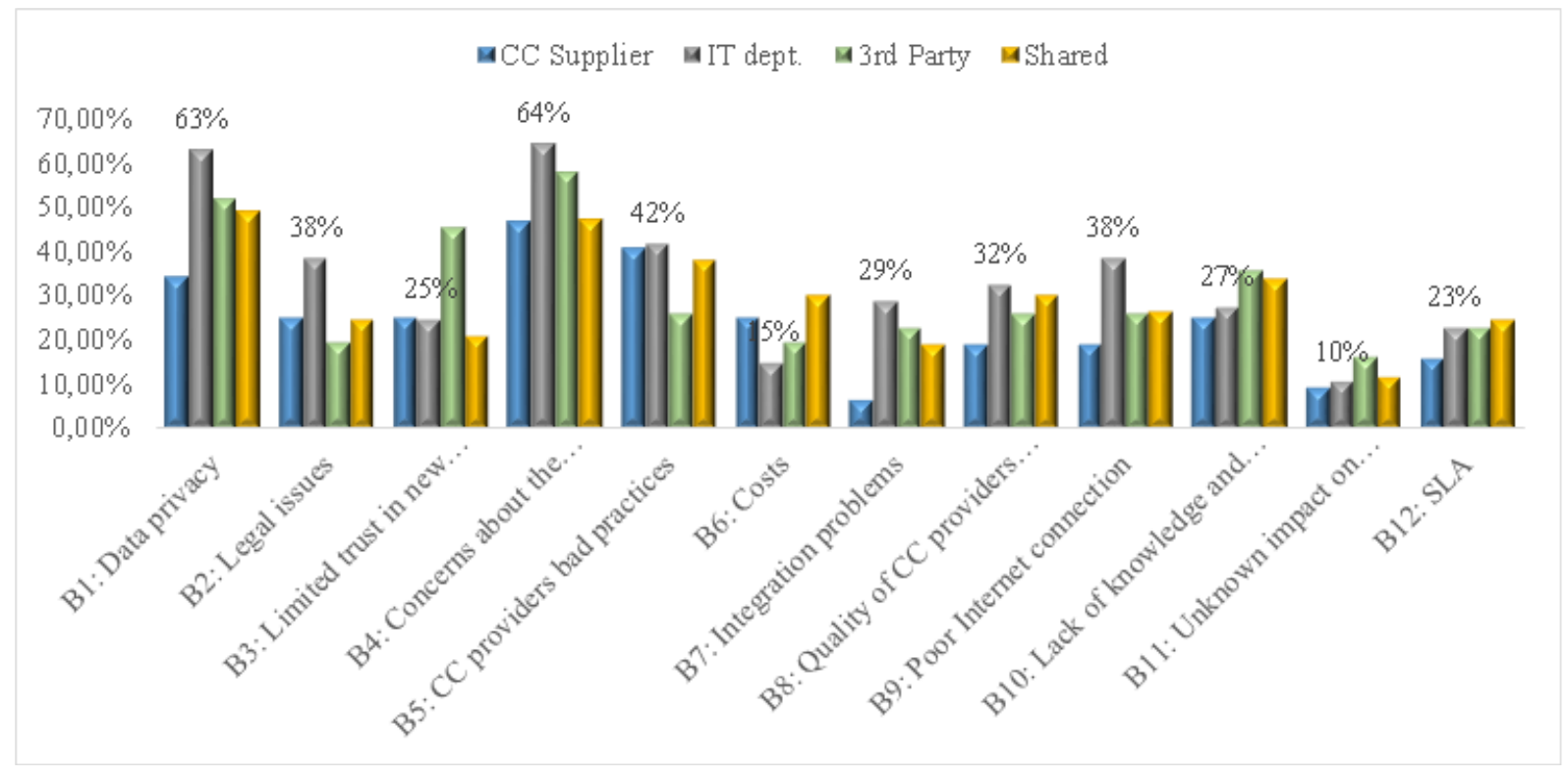

Figure 8. Perception of barriers depending on the entity responsible for the implementation. Source: Own compilation.

\section{Conclusions and Discussion}

Limiting the perception of barriers to the implementation of CC solutions is an important factor in the development of Industry 4.0. The introduction of Cloud Manufacturing requires changes on the scale of the entire company, regarding both technology and business processes, and even concerning business models or organisational culture. SMEs see fewer and fewer barriers in the implementation of new CC models. In the surveyed SMEs group most barriers are perceived by less than $30 \%$ of respondents. Dynamic changes in business models and technologies make entrepreneurs, especially from the SMEs sector, seek solutions to allow for the implementation of $\mathrm{CC}$ in planning and implementing Cloud Manufacturing according to the adopted strategy. The IT strategy is part of the IT system, and the conducted research did not indicate clearly enough that its possession affects the reduction in the perception of barriers. A certain limitation of the study is the fact that four categories were used for the consideration of this impact, no separate Digital Business Strategy or Agile Strategy were considered, assuming that they were included in the adopted survey options. The conducted analysis of the impact of the entity implementing the $\mathrm{CC}$ solution indicates that the perception of individual barriers by respondents is less frequent when the implementation is conducted by the CC services supplier and more frequent when it is carried out by their own IT Department.

It should also be noted, as another limitation of the study, that the results do not indicate the reasons for the perception of barriers, e.g. approx. $90 \%$ of respondents do not see as a barrier the impact that the implementation of the model had on their business. This may indicate either a high level of maturity of these enterprises, or, on the contrary, low awareness of what the 
company can obtain apart from the change of technology itself. External factors may also have influenced the results of the research. Most of the respondents indicated the barriers related to Data privacy and Concerns about the security of data and services. This result could have been influenced by the period in which the research was carried out, which is less than half a year before the entry into force of the General Data Protection Regulation - GDPR. The presented results concern 270 manufacturing enterprises and contribute to the broadening of knowledge about barriers faced by SMEs implementing solutions leading to Cloud Manufacturing. Further research will focus on a greater number of organisations and an analysis of the reasons for the perception of barriers.

\section{References}

1. Al Mabhouh, A., Alzaza, N.S. (2015). Barriers for Adoption of Cloud Computing in the Palestinian Industries. European Journal of Computer Science and Information Technology. Vol. 3, No. 4, pp. 43-57, August, Retrieved from http://www.eajournals.org/ wp-content/uploads/Barriers-for-Adoption-of-Cloud-Computing-In-the-PalestinianIndustries.pdf, 5.7.2019.

2. Alkhalil, A., Sahandi, R., John, D. (2013). Migration to Cloud Computing - The Impact on IT Management and Security. In International Workshop on Cloud Computing and Information Security. https://doi.org/10.2991/ccis-13.2013.46.

3. Arendt, Ł. (2017). Barriers to ICT adoption in SMEs - how to Bridge Digital Divide? IADIS International Conference e-Commerce 2007. Retrieved from https://www.academia.edu/ 2349490/Barriers_to_ICT_adoption_in_SMEs_how_to_bridge_the_digital_divide, 5.7.2019.

4. Baines, T., Lightfoot, H., Peppard, J., Johnson, M., Tiwari, A., Shehab, E., Swink, M. (2009). Towards an operations strategy for product-centric servitization. International Journal of Operations \& Production Management, 29(5), 494-519. htps://doi.org/10.1108/ 01443570910953603

5. Barann, B., Hermann, A., Cordes, A-K., Chasin, F., Becker, J. (2019). Supporting Digital Transformation in Small and Medium-sized Enterprises: A Procedure Model Involving Publicly Funded Support Units. Proceedings of the 52nd Hawaii International Conference on System Sciences. https://hdl.handle.net/10125/59935, 07.07.2019.

6. Bell, D. (1974). The Coming of Post-Industrial Society. New York: Harper Colophon Books.

7. Bharadwaj, A., El Sawy, O.A., Pavlou, P.A., Venkatraman, N.V. (2013). Digital business strategy: toward a next generation of insights. MIS Q, Vol. 37(2), 471-482, https://doi.org/ 10.25300/MISQ/2013/37:2.3. 
8. Computer weekly. (2003). Half of SMEs have no IT strategy. Retrieved from https://www.computerweekly.com/feature/Half-of-SMEs-have-no-IT-strategy, 07.07.2019.

9. Doherty, N., Marples, C.G., Suhaimi, A. (1999). The relative success of alternative approaches to strategic information systems planning: an empirical analysis. Journal of Strategic Information Systems, 8(3), pp. 263-283

10. Dziembek, D. (2018). Cloud Computing - stan obecny i perspektywy rozwoju w Polsce. Nierówności Społeczne a Wzrost Gospodarczy, no. 53, 238-251, https://doi.org/10.15584/ nsawg.2018.1.20.

11. Goerzig, D., Bauernhans, T. (2018). Enterprise Architectures for the Digital Transformation in Small and Medium-sized Enterprises. Procedia CIRP, Vol. 67, pp. 540-545, ISSN 22128271, https://doi.org/10.1016/j.procir.2017.12.257.

12. Gupta, P., Seetharaman, A., Raj, J.R. (2013). The usage and adoption of cloud computing by small and medium businesses. International Journal of Information Management, Vol. 33, Iss. 5, pp. 861-874, ISSN 0268-4012, https://doi.org/10.1016/j.ijinfomgt. 2013.07.001.

13. Krok, E. (2017). Chmura obliczeniowa w przedsiębiorstwie. Organizacja i Zarzadzanie: Scientific Quarterly, no. 1(37), pp. 81-96.

14. Oleśków-Szłapka, J., Stachowiak, A., Batz, A., Fertsch, M. (2017). Level of Innovation in SMEs, the Determinants of Innovation and their Contribution to Development of Value Chains. Procedia Manufacturing, Vol. 11, pp. 2203-2210, ISSN 2351-9789, https://doi.org/10.1016/j.promfg.2017.07.367.

15. Palos-Sanchez, P.R. (2017). Drivers and Barriers of the Cloud Computing in SMEs: the Position of the European Union. Harvard Deusto Business Research, 6, 116-132. https://doi.org/10.3926/hdbr.125.

16. Parys, T. (2015). Bariery wdrożeniowe Cloud Computing oraz ich istotność dla organizacji w ocenie użytkowników. Systemy wspomagania organizacji SWO 2015, pp. 206-218.

17. PWC (2017). The Role of the CIO in Integrating IIoT for Industrial Companies. Retrieved from https://www.pwc.com/m1/en/publications/documents/role-of-cio-in-integrating-iiotfor-industrial-companies.pdf, 07.07.2019.

18. Seman, E.A.A., Salim, J. (2013). A Model for Business-IT Alignment in Malaysian Public Universities. Procedia Technology, Vol. 11, pp. 1135-1141, ISSN 2212-0173, https://doi.org/10.1016/j.protcy.2013.12.305.

19. Sierska, J., Jaada, K.S. (2018). Cloud manufacturing: a service-oriented manufacturing paradigm. A review paper. Engineering Management in Production and Services, Vol. 18, Iss. 1, https://doi.org/10.1515/emj-2018-0002.

20. Silvius, A.J., De Waal, B., Jakobus, S. (2009). Business and IT Alignment; Answers and Remaining Questions. PACIS 2009 - 13th Pacific Asia Conference on Information Systems: IT Services in a Global Environment, 44. 
21. Silvius, A.J. (2007). Business \& IT Alignment in theory and practice. 40th Annual Hawaii International Conference on System Sciences. https://doi.org/10.1109/HICSS.2007.119.

22. Słaby, T., Dwojak, A. (2014). Bariery rozwoju usług na rynku chmur obliczeniowych w Polsce. Studia ekonomiczne, 195, pp. 174-182. Retrieved from https://www.infona.pl/ resource/bwmeta1.element.desklight-efd2a0d7-8016-4ac4-917d-0ee5163eeda7, 07.07.2019.

23. Smits, M., Fairchild, A., Ribbers, P., Milis, K., Geel, E. (2009). Assessing Strategic Alignment to Improve IT Effectiveness. BLED 2009 Proceedings, 15. Retrieved http://aisel.aisnet.org/bled2009/15, 06.07.2019.

24. Sun, H., Hong, C. (2002). The alignment between manufacturing and business strategies: its influence on business performance. Technovation, Vol. 22, Iss. 11, pp. 699-05. ISSN 0166-4972, https://doi.org/10.1016/S0166-4972(01)00066-9.

25. Türkes, M.C., Oncioiu, I., Aslam, H.D., Marin-Pantelescu, A., Dan Topor, I., Capusneanu, S. (2019). Drivers and Barriers in Using Industry 4.0: A Perspective of SMEs in Romania. Processes, vol. 7, 153; doi:10.3390/pr7030153.

26. Weiss, J.W., Thorogood, A. (2011). Information Technology (IT)/Business Alignment as a Strategic Weapon: A Diagnostic Tool. Engineering Management Journal, 23, 2, 0-41, https://doi.org/10.1080/10429247.2011.11431893.

27. Xu, X. (2012). From cloud computing to cloud manufacturing. Robotics and ComputerIntegrated Manufacturing, Vol. 28, Iss. 1, pp. 75-86, ISSN 0736-5845, https://doi.org/10.1016/j.rcim.2011.07.002.

28. Yuqiuge, H. (2016). Cloud Manufacturing Strategic Alignment between Manufacturing Industry and Cloud Computing. Acta Wasaensia, 364, Industrial Management, 43. Retrieved form https://www.univaasa.fi/materiaali/pdf/isbn_978-952-476-715-6.pdf, 06.07.2019. 